\title{
PREDICTION MODEL FOR HOISTING TIME USING LUFFING-TYPE CRANE FOR HIGH-RISE BUILDING CONSTRUCTION
}

\author{
$\underline{\text { Yoonseok Shin }}{ }^{1}$, Chang-Yeon $\mathrm{Cho}^{2 *}$, Jung-Yeol Kim², Heebok Choi ${ }^{3}$, and Moon-Young Cho ${ }^{2}$ \\ ${ }^{1}$ Department of Architectural Engineering, Gyeongnam National University of Science and Technology, \\ Jinju, Korea \\ ${ }^{2}$ Construction Management \& Economy Division, Korea Institute of Construction Technology, \\ Goyang, Korea \\ ${ }^{3}$ Construction Technology Research Institute, Doosan Engineering \& Construction, Seoul, Korea \\ *Corresponding author (cycho@kict.re.kr)
}

\begin{abstract}
Hoisting planning for systematic and efficient vertical transportation is one of the key factors for successful completion in high-rise building construction. However, despite this importance, minimal research has been carried out for predicting hoist time, which is a key player in hoisting planning. Therefore, this study proposed a prediction model for vertical hoisting time using a luffing-type crane. From the results, validation of the model showed the potentiality to apply the actual prediction of hoisting time of a luffing-type crane after additional research.
\end{abstract}

Keywords: Hoisting Time, Luffing-type Crane, High-rise Building

\section{INTRODUCTION}

Over the past decade, the number of high-rise building constructions has increased due to developments in material technology and structural engineering, and due to the necessity for efficient space utilization caused by increasing land prices and the problem of overpopulation in urban areas [1]. In high-rise building construction, successful completion heavily depends on a hoisting plan for systematic and efficient vertical transportation [2]. Especially, the availability of a tower crane inevitably influences the performance of related activities. An inadequate hoisting plan for a tower crane in the early stages of a project can cause problems such as failing to transport resources as required or leaving cranes idle. Despite its significant roles in high-rise building construction, there is not sufficient research for the prediction of vertical hoisting time, which is one of the most important tasks in generating hoisting planning for the crane. Therefore, the objective of this study was to propose a prediction model for vertical hoisting time using a luffing-type crane, which is the most used type of crane in high-rise building construction.

\section{PREDICTION MODEL FOR HOISTING TIME}

\subsection{Simplified hoisting work}

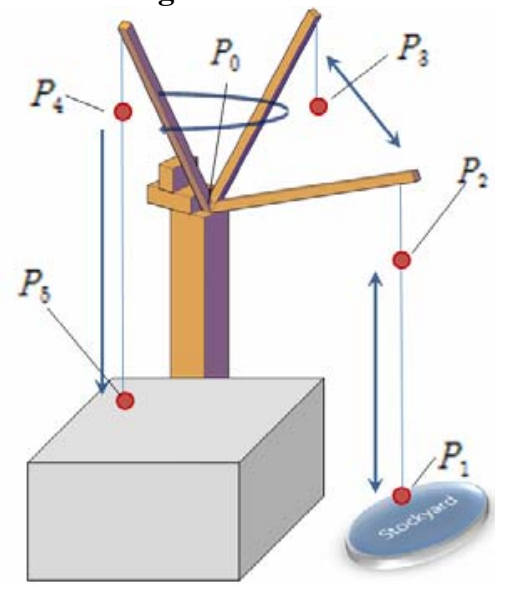

Fig. 1 Simplified model of vertical transportation work In this study, a mathematical model is proposed to represent actual vertical transportation using a luffing-type crane. In order to construct the model, the work process was ideally simplified as five types of repeated cyclic activities such as lifting-up $\left(\overline{P_{1} P_{2}}\right)$, luffing-up $\left(\bar{P}_{2} \bar{P}_{3}\right)$, slewing $\left({\overrightarrow{P_{3}}}_{P_{4}}\right)$, lifting-down $\left(\overline{P_{4} P_{5}}\right)$, and return $\left(\bar{P}_{5} P_{1}\right)$ as shown Fig. 1 


\subsection{Constructing mathematical model}

In order to construct the mathematical model for predicting hoisting time, each co-ordination of material according to crane operation was firstly identified as follows.

-Location of turntable $\left(P_{0}\right)$

$\left(x_{0}, y_{0}, z_{0}\right)=$ Actual location of turntable

-Location of hanging a material up on the hook $\left(P_{1}\right)$

$\left(x_{1}, y_{1}, z_{1}\right)=$ Actual location of stockyard

-Location after hoisting-up $\left(P_{2}\right)$

$\left(x_{2}, y_{2}, z_{2}\right)=\left(x_{1}, y_{1}, z_{0}-10\right)$

-Location after luffing-up $\left(P_{3}\right)$

$\left(x_{3}, y_{3}, z_{3}\right)=\left(\frac{x_{2} \times m+x_{0} \times n}{m+n}, \frac{y_{2} \times m+y_{0} \times n}{m+n}\right.$, $\left.\sqrt{\left(x_{0}-x_{2}\right)^{2}+\left(y_{0}-y_{2}\right)^{2}+\left(z_{0}-z_{2}\right)^{2}} \times(\operatorname{SIN}(\alpha+\beta)-\operatorname{SIN} \beta)+z_{2}\right)$ then, ' $P_{3}$ ' becomes the point of internal division between ' $P_{0}$ ' and ' $P_{2}$ ' as ' $m: n$ '; $m=\sqrt{\left(x_{0}-x_{5}\right)^{2}+\left(y_{0}-y_{5}\right)^{2}}$ and $n=\left(\sqrt{\left(x_{0}-x_{2}\right)^{2}+\left(y_{0}-y_{2}\right)^{2}}-m\right)$. Also, as shown fig. 2 , the co-ordination of ' $z_{3}$ ' can be calculated using the sine function.

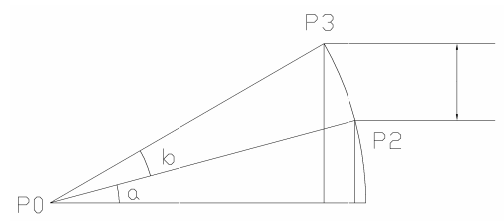

Fig. 2 Vertical movement after luffing-up -Angle of boom slewing $\left({ }^{\theta}\right)$ and location after slewing $\left(P_{4}\right)$ ' $\theta$ ' can be calculated by using the Second Law of Cosines and inverse cosine function as follows;

$$
\theta=\cos ^{-1}\left(\frac{\left(\overline{P_{0} P_{3}}\right)^{2}+\left(\overline{P_{0} P_{5}}\right)^{2}}{2 \times\left(\overline{P_{0} P_{3}}\right) \times\left(\overline{P_{0} P_{5}}\right)}\right)
$$

In addition, co-ordinations of ' $P_{4}$ ' are as follows;

$\left(x_{4}, y_{4}, z_{4}\right)=\left(x_{5}, y_{5}, z_{2}\right)$

-Location after hoisting-down $\left(P_{5}\right)$

$\left(x_{5}, y_{5}, z_{5}\right)=$ Actual location of installation or temporary stockyard

Based on the origin capacity of the crane, work time at each step can be subsequently calculated by dividing the distance or angle by velocity. Therefore, the vertical hoisting time using a luffing-type crane will be the total sum of these times.

\section{VALIDATION OF THE MODEL}

The proposed model in this study was applied in two real construction projects to verify its applicability and effect in predicting the vertical hoisting time. These projects are high-rise buildings constructed in Korea. 20 data using HKL 1250, which is a luffing type crane, of vertical transportation were applied to the model. Also, the average error rate of predicting hoisting time by the model was $15 \%$ when the operation efficiency was $80 \%$.

\section{CONCLUSION}

In this study, a prediction model for vertical hoisting time using a luffing-type crane in high-rise building construction was proposed. In addition, the validation of the model was performed to verify its applicability. Consequently, this model showed the potentiality to apply the actual prediction of hoisting time of a luffing-type crane after additional research. In a further study, the authors will try to identify a method to conclude the appropriated operation efficiency of the crane under various site conditions. Also, we will propose an advanced model to treat two or more cranes simultaneously.

\section{ACKNOWLEDGEMENT}

This research was supported by a grant (Code\# '09 R\&D A01) from the Cutting-edge Urban Development Program funded by the Ministry of Land, Transport and Maritime Affairs of the Korean government.

\section{REFERENCES}

[1] Shin, Y., Cho, H, Kang, K.I., "Simulation model incorporation genetic algorithms for optimal temporary hoist planning in high-rise building construction”, Automation in Construction, in press, 2010.

[2] Lee, H.S., Chae, H.D, Jang, M.H., “Development of Tower Crane Planning Process in High-rise Building Projects”, Journal of Architectural Institute of Korea, Vol. 18(6), 2002. 